\title{
Comparison Study between Drugs (Orlistat and Chitocal) and Food Supplements (Green Tea and Apple Cider Vinegar) for Weight Loss and Hepatoprotection in Rats *Hassan M. Bukhari ${ }^{1}$, Seham E. Zahran ${ }^{1,2}$, El-Sayed H. Bakr ${ }^{1,3}$, Fayaz A. Sahibzadah ${ }^{1}$, Eslam A. Header ${ }^{1,3}$ \\ ${ }^{1}$ Department of Clinical Nutrition, Faculty of Applied Medical Sciences, Umm Al-Qura University, Makkah, KSA \\ ${ }^{2}$ Department of Food Hygiene and Control, Animal Health Research Institute, Egypt. \\ ${ }^{3}$ Department of Nutrition and Food Sciences, Faculty of Home Economics, \\ Menoufia University, Shebin El Kom, Egypt. \\ * Corresponding author: Hassan M. Bukhari, E-mail: hmbukari@uqu.edu.sa, Mobile: 966560248841, \\ Umm Al Qura University, Makkah, Al badyah, Taif Road, Faculty of Applied Medical Sciences, Clinical nutrition department. 8WJQ+PH, Alawali, Mecca 24381
}

\begin{abstract}
Background: Obesity is a major problem in Saudi Arabia. Pharmaceutical solutions were sought for treatment. Chemical formula might lead to major health side effects. Meanwhile, the use of herbal formula is alleged to be safe. Green tea and apple vinegar are some of these products.

Objective: The study aimed to measure the effect of green tea and apple vinegar on obesity and liver status compared to medical drugs.

Materials and methods: Thirty-six adult male albino rats were divided into normal control, and other five groups fed on high caloric and hyperlipidemic diets. They were control positive and the rest 4 groups were treated with different formula (green tea, apple cider vinegar, orlistat and chitocal).

Results: All treated groups showed significant decrease in body weight when compared to control positive. Rats administered with orlistat and chitocal showed the highest significant decrease in body weight gain (BWG) when compared to control positive. Moreover, all tested groups enhanced liver functions especially chitocal and apple cider vinegar groups which showed the highest effect in ALT. Orlistat and green tea groups came in second level. Conclusion: Although, no poor effect of chemical drugs found, natural products can provide the positive effect with no risk. Apple cider vinegar was the best natural weight control formula.
\end{abstract}

Key words: Apple cider vinegar, Chitocal, Green tea, Obesity, Orlistat, Rats.

\section{INTRODUCTION}

Obesity is now recognized as a disease condition that has a direct impact on morbidity and mortality. A third of the adult American population is now obese (age-adjusted prevalence of obesity $33.8 \%$ in 2007-2008), and another third is overweight, for a combined prevalence of $68 \%{ }^{(1)}$. The obesity epidemic is spreading around the world, making obesity a global public health problem. Although the etiology of this global epidemic is multifactorial, most individuals suffer from the condition. Thus, you will be pleased to find a relatively easy way to lose weight ${ }^{(2)}$. Alternative medicines have been used worldwide for many years to treat illness or promote health ${ }^{(3)}$. Recent data on the use of nutritional supplements for weight loss indicates that more than $30 \%$ of those who have attempted to lose weight seriously have used the supplement without a prescription ${ }^{(4)}$.

Weight loss and reduced visceral fat are known to cause lower blood pressure and lipid levels and the occurrence of cardiovascular disease (CVD) (5). Various agents for lowering lipid (Chitosan drug) and body weight (Orlistat drug) are available on the market. However, most of these causes potentially some side effects such as nausea and vomiting. More serious side effect is the interaction with warfarin, which might affect users with heart problems. If used for long time it could reduce the absorption of fatsoluble vitamins and some minerals. For this reason, much attention has been paid to herbs and plant extracts that offer similar benefits without the side effects ${ }^{(6)}$.

Green tea reduces adipose tissue weight in obese animal models ${ }^{(7)}$, and has a pronounced effect on lipid metabolism in hyperlipidemia models ${ }^{(8)}$. The visceral weight loss and lipid profile that improve the effect of green tea in rats may have been due to an enhancing thermogenesis and fat oxidation (9), inhibiting gastric and pancreatic lipases, or suppressing appetite and reduction in food intake ${ }^{(10)}$. The health-promoting effects of green tea have been mainly attributed to the catechins content.

About the acetic acid there is limited scientific support for the claim that apple cider vinegar can promote weight loss. In this respect Kondo et al. ${ }^{(11)}$ found that obese people who consumed acetic acid daily for 12 weeks experienced significant decreases in body weight, abdominal fat, waist circumference, and triglycerides.

Bouderbala et al. ${ }^{(12)}$ demonstrated that acetic acid may help prevent the accumulation of body fat and some fats in the liver, indicating that the metabolic disturbances caused by a high-fat diet would be regulated due to the effect of satiety by consuming 
apple cider vinegar. It also reduces fats and glucose in the blood. Moreover, it appears to prevent the risks of arteriosclerosis.

Accordingly, our research aimed to compare the effectiveness of drugs (Orlistat and chitocal) and food supplements (Green tea and apple cider vinegar) on weight loss and hepatoprotective effect in obese rats.

\section{MATERIALS AND METHODS}

Drugs: The drugs used in this investigation were orlistat and chitocal.

Food Supplements: The food supplements used in this investigation were green tea and apple cider vinegar.

Rats: Thirty-six (36) adult male albino rats Sprague Dawley were used in the research.

Basal Diet: Basal diet consisted of casein, sucrose, corn oil, choline chloride, vitamins mixture, mineral mixture, cellulose, and corn starch.

\section{Extracts and drugs preparation:}

1. Green tea; $10 \mathrm{~g}$ green tea was added to $100 \mathrm{ml}$ of boiling water and was steeped for $15 \mathrm{~min}$. The infusion was cooled to room temperature and then filtered. Tea leaves were extracted a second time with $100 \mathrm{ml}$ of boiling water and filtered, and two filtrates were combined to obtain a $5 \%$ tea aqueous extract $(5 \%$ tea leaf/100 $\mathrm{ml}$ water). Green tea extract (GTE) was orally administered to rats at a dose of $1 \mathrm{ml} / 100 \mathrm{~g}$ body weight.

2. Apple cedar vinegar, used as $6 \% \mathrm{v} / \mathrm{v}$ and the dose was $0.8 \mathrm{ml} / \mathrm{kg}$ body weight of rats.

3. Drugs: Orlistat and chitocal were completely dissolved in $1 \%(\mathrm{v} / \mathrm{v})$ acetic acid solution. The mixture was forcefully shaken for a full day at room temperature.

\section{Design of the experiment:}

Thirty-six (36) adult male albino rats, which kept individually in well-aerated cages and fed on basal diet for one week for adaptation, in animal house of Faculty of Medicine, Umm Al Qura University, KSA.

Ethical approval: for animal handling acts for the University of Um Al Qura was obtained and followed across the experiment.

Rats were divided into equally six groups ( $\mathrm{n}=6$ rats) one group was kept as normal rats and the remaining five groups were fed on high caloric and hyperlipidemic diets to become obese as follows:

Group (1): Normal rats control (- ve) fed on basal diet all over the experiment period.
Group (2): Obese control group control (+ ve) fed on hyperlipidemic diet.

Group (3): Obese rats with oral administration of 1 $\mathrm{ml} / 100 \mathrm{~g}$ body weight green tea extract for 28 consecutive days.

Group (4): Obese rats with oral administration of 0.8 $\mathrm{ml} / \mathrm{kg}$ body weight of apple cider vinegar for 28 consecutive days.

Group (5): Obese rats with oral administration of 60 $\mathrm{mg}$ per $\mathrm{kg}$ body weight orlistat for 28 consecutive days.

Group (6): Obese rats with oral administration of 7.5 mg per kg body weight chitocal for 28 consecutive days.

\section{Biological evaluation:}

During the experimental period, the diet consumed was recorded every day; body weight for all rats was recorded every week and the food consumed were calculated. Many biological evaluations of the different diets were conducted using body weight gain (BWG), food efficiency ratio (FER). The next formulas were applied ${ }^{\left({ }^{(13)}\right.}$.

BWG $(\mathrm{g})=$ Final weight - Initial weight/Initial weight $\mathrm{x} 100$

FER $=\quad$ Gain in body weight $(\mathrm{g}) /$ Food Intake $(\mathrm{g})$

At the end of the experimental period, rats were fasted overnight then were sacrificed. The serum was separated by collecting blood samples, allowing to clot for 15 minutes at $24-25 \mathrm{C}^{\circ}$ then centrifuged at 3000 $\mathrm{rpm}$. Serum was kept frozen till analysis. Liver, heart, kidneys, lungs, spleen, stomach, duodenum and colon were removed, cleaned and weighed then preserved in formalin.

Biochemical analysis: Lipids profiles and liver enzymes functions were determined in the serum.

\section{Statistical analysis:}

Statistical analysis were performed using SPSS program V. 22 for mean, SE and ANOVA test was applied as required. Data were presented in tables. P less than 0.05 was considered significant.

\section{RESULTS}

\section{Biological evaluation}

It could be observed from table (1) that there was an increase in BWG in control positive group. Concerning food intake (FI), obese rats administered with orlistat group showed significant decrease when compared to control positive group. BWG\% was significantly different from control positive group for all treatments, yet, rats administered with orlistat showed the highest significant decrease when compared to control positive group. 
Table (1): Biological effect of orlistat, chitocal, green tea and apple cider vinegar on body weight gain (BWG\%), food intake (g) food efficiency ratio (FER) and adiposity index (Ad.I) of obese rats

\begin{tabular}{|c|c|c|c|c|c|c|}
\hline Proups & $\begin{array}{l}\mathrm{C}-\mathrm{ve} \\
(\mathrm{N}=6)\end{array}$ & $\begin{array}{l}\mathrm{C}+\mathrm{ve} \\
(\mathrm{N}=6)\end{array}$ & $\begin{array}{c}\text { Orlistat } \\
(\mathrm{N}=6)\end{array}$ & $\begin{array}{c}\text { Chitocal } \\
(\mathrm{N}=6)\end{array}$ & $\begin{array}{c}\text { Green tea } \\
\quad(\mathrm{N}=6)\end{array}$ & $\begin{array}{l}\text { Apple cider } \\
\text { vinegar } \\
(\mathrm{N}=6)\end{array}$ \\
\hline & Mean \pm SE & Mean \pm SE & Mean \pm SE & Mean \pm SE & Mean \pm SE & Mean \pm SE \\
\hline Initial weight & $223.60 \pm 11.61^{*}$ & $261.80 \pm 8.46$ & $293.70 \pm 11.90^{*}$ & $295.80 \pm 11.98$ & $294.20 \pm 13.68$ & $322.80 \pm 6.62$ \\
\hline Final weight & $241.40 \pm 13.62^{* *}$ & $307.60 \pm 10.10$ & $250.80 \pm 12.32^{* *}$ & $281.20 \pm 12.02$ & $286.80 \pm 14.98$ & $312.60 \pm 7.51$ \\
\hline Food Intake & $24.14 \pm 1.36^{* *}$ & $30.76 \pm 1.01$ & $25.08 \pm 1.23^{* *}$ & $28.12 \pm 1.20$ & $28.68 \pm 1.50$ & $31.26 \pm 0.75$ \\
\hline BWG\% & $7.69 \pm 0.71^{*}$ & $17.85 \pm 3.16$ & $-14.58 \pm 2.7^{* * * *}$ & $-4.98 \pm 0.86^{* * *}$ & $-2.75 \pm 0.82^{* * * *}$ & $-3.18 \pm 1.11^{* * *}$ \\
\hline FER & $0.31 \pm 0.02^{*}$ & $0.57 \pm 0.10$ & $-0.63 \pm 0.14^{* * *}$ & $-0.18 \pm 0.04^{* * *}$ & $-0.11 \pm 0.04^{* * *}$ & $-0.11 \pm 0.04^{* * * *}$ \\
\hline Ad.I \% & $2.22 \pm 0.14^{* * *}$ & $3.52 \pm 0.04$ & $1.92 \pm 0.10^{* *}$ & $1.88 \pm 0.05^{* * * *}$ & $2.31 \pm 0.12^{* * *}$ & $2.54 \pm 0.08^{* * * *}$ \\
\hline
\end{tabular}

$*$ Differences are significant at $5 \%(\mathrm{P}<0.05)$.

$* *$ Differences are significant at $1 \%(\mathrm{P}<0.01)$.

*** Differences are significant at $0.1 \%(\mathrm{P}<0.001)$.

Data presented in table (2) shows the effect of extracts on organs weights (Liver, Lung, Heart, Spleen and Kidneys) in obese rats. Lungs were getting bigger when orlistat and green tea were consumed compared to positive control. Only orlistat increased liver size significantly. Apple vinegar reduces the colon and stomach size.

Table (2): Biological effect of orlistat, chitocal, green tea and apple cider vinegar on internal organs weight to body weight ratio of rats fed on high-fat diet

\begin{tabular}{|c|c|c|c|c|c|c|}
\hline \multirow{2}{*}{$\begin{array}{l}\text { Internal } \\
\text { organs }\end{array}$} & C -ve & $\mathrm{C}+\mathrm{ve}$ & Orlistat & Chitocal & Green tea & $\begin{array}{l}\text { Apple cider } \\
\text { vinegar }\end{array}$ \\
\hline & Mean \pm SE & Mean \pm SE & Mean \pm SE & Mean \pm SE & Mean \pm SE & Mean \pm SE \\
\hline $\begin{array}{l}\text { Renosomatic } \\
\text { index }\end{array}$ & $0.003 \pm 0.000$ & $0.003 \pm 0.000$ & $0.004 \pm 0.000$ & $0.004 \pm 0.000$ & $0.004 \pm 0.000^{* *}$ & $0.003 \pm 0.000$ \\
\hline $\begin{array}{l}\text { Lung somatic } \\
\text { index }\end{array}$ & $0.007 \pm 0.001^{*}$ & $0.005 \pm 0.000$ & $0.007 \pm 0.000^{* *}$ & $0.009 \pm 0.001^{* * *}$ & $0.011 \pm 0.002^{*}$ & $0.006 \pm 0.001$ \\
\hline $\begin{array}{l}\text { Splenosomatic } \\
\text { index }\end{array}$ & $0.003 \pm 0.000$ & $0.003 \pm 0.000$ & $0.003 \pm 0.000$ & $0.003 \pm 0.000$ & $0.002 \pm 0.000$ & $0.003 \pm 0.000$ \\
\hline $\begin{array}{l}\text { Hepatosomatic } \\
\text { index }\end{array}$ & $0.025 \pm 0.001$ & $0.026 \pm 0.001$ & $0.029 \pm 0.001^{*}$ & $0.026 \pm 0.001$ & $0.027 \pm 0.001$ & $0.025 \pm 0.001$ \\
\hline $\begin{array}{l}\text { Cardiosomatic } \\
\text { index }\end{array}$ & $0.003 \pm 0.000$ & $0.003 \pm 0.000$ & $0.003 \pm 0.000$ & $0.003 \pm 0.000$ & $0.003 \pm 0.000$ & $0.003 \pm 0.000$ \\
\hline $\begin{array}{l}\text { Stomach somatic } \\
\text { index }\end{array}$ & $0.008 \pm 0.001$ & $0.007 \pm 0.000$ & $0.007 \pm 0.000$ & $0.008 \pm 0.000$ & $0.008 \pm 0.001^{*}$ & $0.006 \pm 0.000$ \\
\hline $\begin{array}{l}\text { Duodenum } \\
\text { somatic index }\end{array}$ & $0.001 \pm 0.000$ & $0.001 \pm 0.000$ & $0.001 \pm 0.000^{*}$ & $0.001 \pm 0.000$ & $0.001 \pm 0.000$ & $0.001 \pm 0.000$ \\
\hline $\begin{array}{l}\text { Colon somatic } \\
\text { index }\end{array}$ & $0.016 \pm 0.001^{* *}$ & $0.013 \pm 0.001$ & $0.014 \pm 0.000$ & $0.013 \pm 0.001$ & $0.011 \pm 0.000^{*}$ & $0.011 \pm 0.000^{*}$ \\
\hline
\end{tabular}

$*$ Differences are significant at $5 \%(\mathrm{P}<0.05)$.

**Differences are significant at $1 \%(\mathrm{P}<0.01)$.

\section{Biochemical analysis}

Data presented in table 3 shows that there was significant increase in serum of total cholesterol, LDL, HDL, VLDL and triglycerides levels in obese rats $(\mathrm{C}+\mathrm{ve})$ when compared to normal groups $(\mathrm{C}-\mathrm{ve})$. All treated groups with extracts showed improvement in lipid profile compared to controls. Rats administered with chitocal and apple cider vinegar showed the highest significant decrease in the level of total cholesterol, followed by green tea extract then orlistat when compared to control negative groups. 
Table (3): Effect of orlistat, chitocal, green tea and apple cider vinegar on lipids profile for obese rats

\begin{tabular}{|l|c|c|c|c|c|c|}
\hline \multirow{2}{*}{$\begin{array}{l}\text { Lipids } \\
\text { profile }\end{array}$} & Groups - ve & C +ve & Orlistat & Chitocal & Green tea & $\begin{array}{c}\text { Apple cider } \\
\text { vinegar }\end{array}$ \\
\cline { 2 - 7 } & Mean \pm SE & Mean \pm SE & Mean \pm SE & Mean \pm SE & Mean \pm SE & Mean \pm SE \\
\hline $\begin{array}{l}\text { Total Lipids } \\
\text { mg/dl }\end{array}$ & $180.75 \pm 5.42$ & $198.00 \pm 5.13$ & $81.05 \pm 1.34^{*}$ & $195.90 \pm 12.58$ & $196.2 \pm 2.9^{*}$ & $195.30 \pm 6.38$ \\
\hline $\begin{array}{l}\text { Cholesterol } \\
\text { mg/dl }\end{array}$ & $62.50 \pm 0.95^{* * *}$ & $89.20 \pm 2.59$ & $\begin{array}{c}58.20 \pm 1.25^{*} \\
* *\end{array}$ & $64.10 \pm 3.80^{* * * *}$ & $67.40 \pm 1.25^{* *}$ & $64.60 \pm 2.18^{* * *}$ \\
\hline $\begin{array}{l}\text { Triglycerides } \\
\text { mg/dl }\end{array}$ & $59.00 \pm 1.55^{* *}$ & $73.10 \pm 3.33$ & $\begin{array}{c}53.30 \pm 2.40^{*} \\
*\end{array}$ & $61.50 \pm 5.27^{*}$ & $64.6 \pm 1.9$ & $65.60 \pm 2.54$ \\
\hline HDL mg/dl & $33.40 \pm 0.69^{* * *}$ & $27.40 \pm 0.37$ & $\begin{array}{c}29.80 \pm 0.33^{*} \\
*\end{array}$ & $31.00 \pm 1.69^{*}$ & $30.50 \pm 1.51^{*}$ & $30.60 \pm 2.47$ \\
\hline VLDLmg/dl & $11.80 \pm 0.31^{* *}$ & $14.62 \pm 0.67$ & $\begin{array}{c}10.66 \pm 0.48^{*} \\
*\end{array}$ & $12.30 \pm 1.05$ & $13.4 \pm 0.40$ & $13.12 \pm 0.51^{*}$ \\
\hline LDL mg/dl & $17.30 \pm 0.45^{* * *}$ & $47.18 \pm 2.22$ & $17.74 \pm 1.41$ & $20.80 \pm 2.04^{* * *}$ & $21.60 \pm 0.47^{* *}$ & $20.88 \pm 0.71^{* * *}$ \\
\hline
\end{tabular}

* Differences are significant at $5 \%(\mathrm{P}<0.05)$.

$* *$ Differences are significant at $1 \%(\mathrm{P}<0.01)$.

*** Differences are significant at $0.1 \%(\mathrm{P}<0.001)$.

Data shown in table (4) indicates that there was significant increase in control positive group for AST, ALT and ALP compared to normal rats. Furthermore, table shows significant decrease in AST, ALT and ALP in all experimental groups when compared with $(\mathrm{C}+\mathrm{ve})$ group. Moreover, chitocal and apple cider vinegar group showed the highest significant decrease in serum ALT then orlistat and green tea group when compared to control positive group.

Table (4): Effect of Orlistat, chitocal, green tea and apple cider vinegar on liver functions; (AST, ALT and ALP) in obese rats

\begin{tabular}{|l|c|c|c|c|c|c|}
\hline \multicolumn{1}{r}{ Groups } & C - ve & C + ve & Orlistat & Chitocal & Green tea & $\begin{array}{c}\text { Apple cider } \\
\text { vinegar }\end{array}$ \\
\cline { 2 - 7 } Parameters & Mean \pm SE & Mean \pm SE & Mean \pm SE & Mean \pm SE & Mean \pm SE & Mean \pm SE \\
\hline AST U/L & $130.7 \pm 9.02^{*}$ & $145.1 \pm 6.2$ & $115.70 \pm 3.43$ & $109.40 \pm 5.59$ & $119.5 \pm 9.6$ & $111.80 \pm 2.69$ \\
\hline ALT U/L & $60.00 \pm 3.06^{* *}$ & $101.8 \pm 4.7$ & $81.90 \pm 10.00^{* *}$ & $47.20 \pm 2.43^{* * *}$ & $61.60 \pm 3.12^{* *}$ & $48.60 \pm 0.62^{* * *}$ \\
\hline ALP U/L & $203.90 \pm 32.46$ & $307.60 \pm 50.03$ & $127.70 \pm 1.11^{* *}$ & $240.00 \pm 24.15$ & $270.10 \pm 34.01$ & $263.60 \pm 10.42$ \\
\hline
\end{tabular}

$*$ Differences are significant at $5 \%(\mathrm{P}<0.05)$.

$* *$ Differences are significant at $1 \%(\mathrm{P}<0.01)$.

\section{DISCUSSION}

Obesity has increased dramatically in past decades and is recognized as a risk factor for developing lifestyle-related diseases ${ }^{(\mathbf{1 4}, \mathbf{1 5})}$. It is reported previously that the subcutaneous fat obesity is less connected to lifestyle-initiated diseases such as CVD and diabetes II than visceral fat obesity ${ }^{(16)}$. Chronic overfeeding leads to uncontrolled inflammatory responses, leading to low-grade systemic inflammation and metabolic disorders, such as insulin resistance ${ }^{(\mathbf{1 7})}$. Although anti-obesity medications (AOMs) are by far overused to lose weight quickly and easily, yet, all international medical and nutritional organizations ask to seek this solution (i.e. using AOMs) if patients failed to lose 5\% of weight just following nutritional and life modifications strategies ${ }^{(18,19)}$.

Our results denote that there were significant increase in BWG (body weight gain) of obese rats as compared to normal rats. Obese rats administered with orlistat, chitocal, green tea and apple cider vinegar groups showed significant decrease when compared to control positive group. Rats administered with orlistst and chitocal showed highest significant decrease when compared to control positive group. Concerning food intake (FI), body weight gain and feed efficiency ratio there were significant increase of obese rats as compared to normal rats. Obese rats administered with orlistat, chitoca, green tea and apple cider vinegar groups showed significant decrease in all previous parameters when compared to control positive group. Rats administered with chitocal group showed the highest significant decrease in body weight gain when compared to control positive group. The results revealed that all experimental groups showed significant decrease in weight of organs (liver, lung, heart, spleen and kidneys) when compared to positive group. Rats administered with green tea extract showed significant decrease in kidneys weight, meanwhile, orlistat and chitocal groups showed significant decrease in lungs weight compared to other groups. These results agreed with Safavi et al. ${ }^{(20)}$ who revealed that using anti-obesity medication (AOM) have significantly greater mean percentage reduction 
in baseline weight than non-users. Moreover, ElSayed and Eslam ${ }^{(21)}$ found that the consumption of green tea extract produced a significant reduction in body weight in obese rats

There were a significant decrease of all lipid profile in rats administered by orlistat and chitocal when compared to control positive group. The orlistat was the best, followed by the apple cider vinegar and then the green tea. These results are supported by Porsgaard et al. ${ }^{(22)}$ who revealed that administration of $25 \mathrm{mg}$ orlistat together with the dietary oils resulted in very small changes for fat that transported form the GIT to the lymphatic system compared to baseline, indicating almost complete inhibition of fat absorption. Orlistat could be acting by inhibiting fat hydrolysis. When compared to positive controls, obese rats that consumed green tea extract had shown a significant decrease in all lipid profiles. Rats administered with green tea extract showed the highest significant decrease in the LDL, VLDL and triglycerides levels while rats administered with apple cider vinegar and chitocal showed the highest significant decrease in the level of total cholesterol, when compared to control positive.

We found significant decrease in level of AST and ALP in rats fed with apple cider vinegar followed by green tea extract. These finding agree with de Dios Lozano ${ }^{(23)}$ who stated that the total and average daily weight gain for obese rats was reduced by vinegar. The patterns of changes in lipid and glucoses was timebond, where within a week up to a month plasma glucose was reduced in obese rats that consumed vinegar. From the $2^{\text {nd }}$ week up to a month of intake of vinegar in obese rats, triglycerides and cholesterol were getting lower. Nonetheless, vinegar did not affect plasma HDL and LDL. Thus, de Dios Lozano ${ }^{(23)}$ has concluded that vinegar might act as protective functional food that inhibit body weight gain by lowering all these parameters if consumed on daily basis. Also, Kondo et al. ${ }^{(24)}$ agreed with our finding as proved that body weight, BMI, visceral fat area, waist circumference, and serum triglyceride levels were significantly lower with vinegar intake. Daily intake of vinegar might be useful in the prevention of metabolic syndrome by reducing obesity, without causing adverse eff ects in studied obese subjects.

Our results cleared that there was highly significant decrease of enzyme level in rats administered by chitocal followed by the orlistat especially ALT and AST enzymes, while orlistat was the best in lowering the ALP enzyme when compared to control positive group. There was a significant decrease of all lipid profile in rats administered by orlistat and chitocal when compared to control positive group where the orlistat was the best. These results are supported by the finding of $\mathbf{X u}$ et al. ${ }^{(25)}$ that chitosan could decrease levels of total cholesterol (TC), low density lipoprotein cholesterol (LDL-C) in plasma $(\mathrm{p}<0.05)$, and TC, total triglyceride $(\mathrm{TG})$ in liver $(p<0.05)$, and increase fecal bile acids excretion $(\mathrm{p}<0.05)$, but the levels of TG and HDL-C in plasma was unchanged $(p>0.05)$, while chitosan could increase hepatic LDL receptor mRNA levels. The plausible explanation for improving lipid metabolism could be explained on the light of that TC and LDL-C regulation at the mRNA expression level on the hepatic cells receptors were upregulated, leading to increase of bile in the stool.

As soon as, Heck et al. ${ }^{(26)}$ investigated orlistat effect as it may decrease the absorption of fat-soluble vitamins, a standard multiple-vitamin supplement is recommended daily during therapy to prevent abnormalities in vitamin serum concentrations. It can lead to severe gastrointestinal discomfort and the modest degree of weight loss may limit the agent's clinical utility. Its long-term safety and effectiveness for weight maintenance, cost-effectiveness of treatment, and overall reduction in obesity-related morbidity and mortality remain to be determined. FDA has added a warning regarding possible severe liver injury to the product information for orlistat (US FDA). The effect of orlistat is conducted on the stomach and small intestine lumen, where it has a reversible inhibiting control over the gastrointestinal lipases

The inhibition of triglyceride digestion reduces lipid absorption, with a subsequent positive effect on the weight control. Orlistat is indicated for the treatment of obesity in combination with a hypocaloric diet. These findings indicate that using of natural supplements used to reduce obesity is safer and with low side effect on human health. These findings are supported by Tziomalos et al. ${ }^{(27)}$ and Hursel and Westerterp-Plantenga ${ }^{(28)}$.

Manipulating a boy's weight with these treatments can be effective and varied by increasing energy expenditure and suppressing appetite. It also decreased the absorption of fats in the intestine by inhibiting pancreatic lipase. Weight loss medication may seem like a solution to obesity. However, potential side effects or adverse drug reactions are always a major public health concern and a major obstacle to developing new drug products. For example, in 1997, due to possible side effects on the heart (heart valves) two drugs (Fenfluramine and dexfenfluramine) were withdrawn. In 2010, sibutramine (Meridia) was also withdrawn due to an increased risk of heart attacks and strokes. That same year, in response to occasional reports of severe liver injury using the weight-loss drug xenical, the Food and Drug Administration (FDA) approved a revised drug label in which safety information about its potential side effects was noted ${ }^{(29)}$.

\section{CONCLUSION}


Orlistat, chitocal, green tea and apple cider vinegar could be used for weight reduction and the side effect for drugs use can be avoided by using the same food supplements as green tea and apple cider vinegar as alternatives natural supplements.

\section{ACKNOWLEDGMENT}

The authors would like to thank Institute of Scientific Research and Revival of Islamic Heritage at Umm Al-Qura University (project \# 43309023) for financial support.

\section{REFERENCES}

1. Flegal K, Carroll M, Ogden C et al. (2010): Prevalence and trends in obesity among US adults, 1999-2008. JAMA., 303: 235-241.

2. Nguyen D and El-Serag H (2010): The epidemiology of obesity. Gastroenterology of Clinical North America, 39: 1-7.

3. Davis M, West A, Weeks W et al. (2011): Health behaviors and utilization among users of complementary and alternative medicine for treatment versus health promotion. Health Serv Res., doi: 10.1111/j.1475-6773. 2011.01270.x.

4. Pillitteri J, Shiffman S, Rohay J et al. (2008): Use of dietary supplements for weight loss in the United States: results of a national survey. Obesity, 16: 790-796.

5. Kromhout D, Menotti A, Kesteloot $H$ et al. (2002): Prevention of coronary heart disease by diet and lifestyle: evidence from prospective cross cultural, cohort, and intervention studies. Circulation, 105: 893-8.

6. Filippatos $T_{2}$ Derdemezis $C_{2}$ Gazi I et al. (2008): Orlistat-associated adverse effects and drug interactions: a critical review. Drug safety, 31(1): 53-65.

7. Crespy V, and Williamson G (2004): A review of the health effects of green tea catechins in vivo animal models. Ournal of Nutrition, 134: 431-40.

8. Woo M, Bok S, Choi M (2009): Hypolipidemic and body fat-lowering effects of Fatclean in rats fed a high-fat diet. Food Chemistry and Toxicology, 47: 2076-82.

9. Juhel C, Armand M, Pafumi Y et al. (2000): Green tea extract (AR25) inhibits lipolysis of triglycerides in gastric and duodenal medium in vitro. Journal of Nutrition Biochemistry, 11(1): 45-51.

10.Kao Y, Hiipakka R, Liao S (2000): Modulation of endocrine systems and food intake by green tea epigallocatechin gallate. Endocrinology, 141: 980-7.

11. Kondo T, Kishi M, Fushimi T et al. (2009): Acetic acid upregulates the expression of genes for fatty acid oxidation enzymes in liver to suppress body fat accumulation. Journal of Agriculture Food Chemistry, 57(13): 5982-6.

12. Bouderbala H, Kaddouri H, Kheroua $O$ et al. (2016): Anti-obesogenic effect of apple cider vinegar in rats subjected to a high fat diet. Ann Cardiolgy Angeiol (Paris), 65(3): 208-13.

13. Chapman D, Gastilla R, Campbell J (1959): Evaluation of protein in foods: 1- A Method for the determination of protein efficiency ratio. Can J Biochem Phys., 37: 679- 86.

14. Visscher $T$ and Seidell $J(2001)$ : The public health impact of obesity. Annu Rev Public Health, 22:355-75.

15. Seidell J (2002): Prevalence and time trends of obesity in Europe. J Endocrinological Investigation, 25: 816-822 14.
16. Fox C, Massaro J, Hoff mann U et al. (2007): Abdominal visceral and subcutaneous adipose tissue compartments: association with metabolic risk factors in the Framingham Heart Study. Circulation, 116: 39-48.

17. Choe S, Huh J, Hwang I et al. (2016): Adipose tissue remodeling: Its role in energy metabolism and metabolic disorders. Journal of Front Endocrinology (Lausanne), 7: 30-36.

18. Stegenga $H$, Haines $A$, Jones $K$ et al. (2014): Identification, assessment, and management of overweight and obesity: summary of updated NICE guidance. BMJ., 349: 6608-12.

19. Curry S, Krist A, Owens D et al. (2019): Behavioral weight loss interventions to prevent obesity- related morbidity and mortality in adults: US preventive services task force recommendation statement. JAMA., 32: 11631171.

20.Safavi R, Lih A, Kirkpatrick S_et al. (2019): Impact of anti-obesity medication initiation and duration on weight loss in a comprehensive weight loss programme. Journal of Obesity and Science Practice. 5(5): 468-478.

21.El-Sayed H and Eslam A (2014): Effect of aqueous extract of green tea (Camellia sinensis L.) on obesity and liver status in experimental rats. International Journal of Pure \& Applied Sciences \& Technology, 22(1): 53-63.

22.Porsgaard T, Straarup E, Mu H et al. (2009): Effect of orlistat on fat absorption in rats: a comparison of normal rats and rats with diverted bile and pancreatic juice. Lipids, 38(10): 1039-43.

23.de Dios Lozano J (2012): Supplementary effects of vinegar on body weight and blood metabolites in healthy rats fed conventional diets and obese rats fed high-caloric diets. J. Med. Plants Res., 6(24):4135-4141.

24. Kondo T, Kishi M, Fushimi T et al. (2009): Vinegar intake reduces body weight, body fat mass, and serum triglyceride levels in obese Japanese subjects. Biosciences, Biotechnology and Biochemistry, 73(8): 1837-43.

25. Xu G, Huang X, Qiu L et al. (2007): Mechanism study of chitosan on lipid metabolism in hyperlipidemic rats. Asia Pac J Clin Nutr., 16: 313-317.

26. Heck M, Yanovski J, Calis K (200): Orlistat, a new lipase inhibitor for the management of obesity. Pharmacotherapy, 20(3): 270-279.

27.Tziomalos K, Krassas G, Tzotzas T (2009): The use of sibutramine in the management of obesity and related disorders: An update. Vasc Health Risk Manag., 5: 441452.

28. Hursel $R$ and Westerterp-Plantenga $M$ (2010): Thermogenic ingredients and body weight regulation. International Journal of Obesity, 34: 659-669.

29. Apovian C, Aronne L, Bessesen D et al. (2015): Pharmacological management of obesity: An endocrine society clinical practice guideline. J Clin Endocr Metab., 100:342-362. 